\title{
19 Sustainable resource output
}

\author{
Towards an approach to a \\ multidimensional environmental \\ assessment of biomass production
}

\author{
H. Böttcher, K. Hennenberg, K. Wiegmann, \\ $M$. Scheffler, and A. Hansen
}

\section{Introduction}

The need for monitoring of the use of biomass resources

The need to use natural resources (e.g. raw materials, air, water, soil, land and ecosystem services through biodiversity) sustainably and efficiently has been identified by science (e.g. Rockström et al. 2009) and generally been recognised by policy (e.g. United Nations 2015). Corresponding initiatives exist at German, European and global level in numerous policy targets and regulations, for example, the German Resource Efficiency Programs (ProgRess, ProgRess II), the Roadmap to a Resource Efficient Europe, and the Resource Panel of the United Nations Environment Program.

The concept of planetary boundaries (Rockström et al. 2009) has established a visual concept for assessing the state of environmental indicators at the global scale. More recent research highlighted the need to consider interactions between indicators and the regional heterogeneity of the processes underpinning the boundaries (Steffen et al. 2015) but also the need to improve the exchange between science and global policies regarding the definition of these boundaries (Galaz et al. 2012).

Successful implementation of sustainable use of natural resources requires a comprehensive monitoring and assessment system. Such a system uses a range of indicators and metrics and tracks them over time and with relation to specific targets to design and to evaluate the path to sustainable resource use (Pavlovskaia 2014). The bioeconomy, or biobased economy, has not only become a technical term for summarising production systems relying on biomass resources but is also seen as an overarching concept for taking a holistic and systems' perspective on the involved sectors. In fact, O'Brien et al. (2015) proposed a systems dynamics approach that is needed to implement a monitoring system for the bioeconomy.

\section{Limits to the concept of resource efficiency}

A common metric to supporting monitoring and assessments on the sustainable use of (natural) resources, in general, is resource efficiency 
(Huysman et al. 2015). Focusing on the field of land use and biomass production, this can be defined as the ratio of a specific utility or output of a biomass production system and the associated specific input, consumption or use of natural resources related to biomass production (for instance crop yield/ area). Another approach for assessing resource efficiency is the concept of ecoefficiency (WBCSD 2006) defined as the ratio between utility and environmental impacts (for example crop yield/water demand). It is a concept that corresponds to the concept of resource efficiency but is widening the input to environmental impacts.

The utility associated with land use and biomass production is not only provided by the sale of crop products (plant or animal products), but also by the provision of other ecosystem services (TEEB 2010). Following the concept of ecosystem services, the notion of utility can be broadened to include supply services, regulatory services and cultural services. Mere biomass production can be considered a supply service, but it uses other ecosystem services to effectively deliver it, often impacting them negatively. Theoretically, it is desirable to include as many ecosystem services in consideration of utility as possible. However, there is a challenge of identifying, quantifying and integrating appropriate indicators (Albert et al. 2016). The concept of ecosystem services allows a consideration of the multidimensional benefits but requires the dimensions to be brought to a common scale of values what can be difficult.

Existing approaches differ regarding the selection of indicators or the environmental aspects covered. These may be very specific, for example, referring to soil erosion, or very general, referring to land as a natural resource. Examples are the framework of human appropriation of net primary production (HANPP; Haberl et al. 2007) or the concept of material input per service unit (MIPS; Schmidt-Bleek 1998). An explicit aggregation of indicators of different dimensions, however, reduces interpretability of the indicator as it reduces the transparency of the approach when a conversion to a common metric has to be done with certain assumptions (Pavlovskaia 2014). The approach of MIPS, for example, cannot be used for assessing specific outputs (e.g. emissions) or specific environmental impacts (e.g. N-balance; Mancini et al. 2012). Indicators must be able to provide quantitative measures that allow an actual assessment and comparison of systems. Therefore, multidimensional approaches are used in sustainability assessments that typically present indicators side by side.

A multi-dimensional assessment requires not necessarily a full integration of indicators into common physical units but a standardisation of the dimensions to be considered. Thus, water quality and greenhouse gas emissions as different indicators can hardly be physically combined. However, they can be compared through scaling e.g. regarding the degree of target achievement of a reduction target or the relative exceedance of limits.

Both resource efficiency and eco-efficiency face another critical limitation that must be taken into account when applied as indicators for the evaluation 
of sustainable production systems. They do not assess the absolute state of resources nor the transgression of sustainability constraints (i.e. leakage effects). Despite increasing resource efficiency, i.e. decreasing input per output produced, the demand for natural resources may increase due to population growth and changing patterns of consumption. Therefore, a relative decoupling of resource use and economic growth by increasing resource efficiency is not sufficient for sustainable resource use and successful resource conservation.

In this paper, we present a new metric for assessing the sustainability of use of natural resources for biomass production by combining existing concepts of resource efficiency and environmental assessment to the sustainable resource output (SRO) and test the metric in two case studies.

\section{Methods}

\section{The concept of sustainable resource output}

Sustainable resource output can be considered an extension to the classic concept of resource efficiency. In addition to the utility of production and the utilisation of natural resources, it also includes thresholds and limits to natural resource use. These thresholds, if exceeded, cause the metric to be set to zero. The benefits gained through the use of natural resources can also be included. This allows production systems of different productivity to be compared by looking at specific indicators.

There are two elements required for calculating SRO (see Figure 19.1). The absolute utility of biomass production $\mathrm{U}$ is normalised in order to assess systems relative productivity $\mathrm{U}^{\prime}(0=$ low productivity, $1=$ high productivity) with $\mathrm{U}^{\prime} \in\{\mathrm{a} \in \mathbb{R} \mid 0 \leq \mathrm{a} \leq 1\}$. The maximum and minimum values need to be defined, either from literature or from model simulations with alternative scenarios. $U$ can be defined narrowly to include only

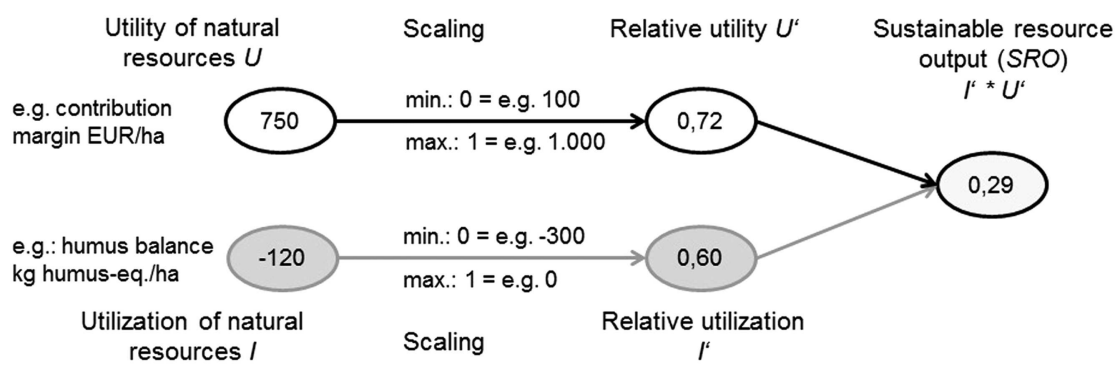

Figure 19.1 Calculation of sustainable resource output SRO from normalised relative utilisation (resource conservation) $\mathrm{I}^{\prime}$ and normalised relative utility $\mathrm{U}^{\prime}$ of natural resources with exemplary figures. 
revenues from biomass production but also expanded to include monetised ecosystem services. In any case, assumptions for deriving utility values need to be clearly documented.

Similarly, the absolute value for the use of natural resources I must be normalised into a relational scaling system. This makes different indicators comparable and is used for assessing the degree of resource utilisation or resource conservation I' (for example, $0=$ low resource conservation, 1 = high resource conservation) with $\mathrm{I}^{\prime} \in\{\mathrm{a} \in \mathbb{R} \mid 0 \leq \mathrm{a} \leq 1\}$. If production reaches an intensity that causes the sustainable use of resources to exceed threshold values, it is set as zero. Such limit and tolerance values can often be taken from literature, from current legislation, as well as from scenario modelling. In the latter case, two guard railing scenarios are established that provide tolerable maximum and minimum values for a certain indicator. SRO then results from the product of scaled relative utility $\mathrm{U}^{\prime}$ and scaled relative utilisation (resource conservation) $\mathrm{I}^{\prime}$.

Four steps for assessing the sustainability of biomass production systems should be applied for deriving the two elements needed for the calculation of SRO:

- System definition: It determines the system boundaries of the assessment and the functional unit for the product generating the utility of natural resources $\mathrm{U}$. It is an important prerequisite and often set through the model or assessment tool applied, database, indicators and variables selected. Klöpffer and Grahl (2012) highlight that not only the functional unit needs to be identical, it also needs to be functionally equivalent, e.g. not only the energy unit needs to be the same but also the type of energy.

- Assessment: Depending on the database used, indicators need to be selected that are used to assess resource utilisation I. Indicator selection is an important step of the analysis as it forms the frame for interpretability of results. Indicators should be chosen in a way that considers the aim of the analysis (Albert et al. 2016). Indicators for assessing land use refer typically either to the area or the intensity of land use (Erb 2015).

- Reference: This includes the description of a reference system and variants, e.g. generated by model simulations through a sensitivity analysis or from literature. The choice of the reference system determines the level of indicator performance for a specific system, and is a critical element of the analysis. It needs to be well documented and credible. For production systems of biomass, it is reasonable to establish a reference that presents a scenario without biomass extraction (Koponen et al. 2018).

- Presentation and interpretation: This step determines which type of scaling or standardisation is used to bring indicators into a format that makes them comparable and in which form they are graphically displayed. Interpretation can further introduce prioritisation or weighting of single indicators when aggregating or interpreting results. Both presentation and interpretation of the results must take into account the assumptions made in earlier steps as well as uncertainties of the calculation. 


\section{Case study descriptions}

\section{System definition}

We tested SRO for two production systems, one from agriculture and one from forestry. The systems were designed to reflect different forest management and farm operations:

- Crop and livestock production (different levels of intensity of cash crop production, feed production and grassland management).

- Forestry (spruce forests, alternative scenarios of forest management change and management intensity).

Based on alternative scenarios reflecting different levels of production intensity in the individual systems, it was determined to what extent resource output changed in the scenarios compared to the reference (see detailed system descriptions in Böttcher et al. 2020).

The production systems were set up as artificial management units representing typical situations in agriculture and forestry in Germany, as they can be observed in the field. However, the size of the management units is higher than those of typical private enterprises operating in the field. The aim was to model sufficiently large units to capture landscape effects and to allow for management shifts without disruption. Therefore, the study provides only limited guidance for management decisions at the farm or forest stand level but is rather oriented towards decisions at larger scale level.

Ideally, the utility I associated with land use and biomass production should also include the provision of other ecosystem services. Although the concept of SRO allows such an inclusion, we limited the analysis to the sale of agricultural or forestry products, i.e. the contribution margin (short: margin). The margin is defined as the monetary amount of revenue (product quantity times price) less variable costs of production. Alternative parameters for mapping the benefits could be gross value added, the revenue, dry biomass production, or the energy or protein production.

The utilisation of natural resources $U$ was determined with the help of indicators that describe the impact of the production system on natural resources. The following indicators were considered in the system crop and livestock production:

- Greenhouse gas emissions: given as $\mathrm{kg} \mathrm{CO}_{2}$ eq. per ha and year, and derived from area, crops, nitrogen requirements, yields and application of manure;

- Humus balance: given as humus equivalents in $\mathrm{kg} \mathrm{C}$ per ha, resulting from the humus balance of crop rotation, catch crops, crop residues and the application of manure;

- Nitrogen balance: given as $\mathrm{kg}$ nitrogen surplus per ha and year based on nutrient inputs into and flows out of the system (farm gate balance); 
- Nutrient contamination of water: given as a percentage of the area with a nitrogen balance greater than $50 \mathrm{~kg} / \mathrm{ha}$, derived from the calculated nitrogen balances.

- Biodiversity: expressed as biotope values, which, for example, take account of the proportion of land used for the cultivation of flowering strips and fallow land, the number of crops in crop rotation, the absence of fertilisers and the proportion of grassland.

Indicators for assessing SRO in forestry were:

a Growing stock: given as cubic meters of wood per ha, calculated as a single tree volume and aggregated to stand level growing stock, differentiated by tree species groups (beech, oak, other broadleaf species, spruce, fir, Douglas fir, pine, and larch).

b Growing stock increment: represented as cubic meters of wood increment per ha and year.

c Harvest amount: given as cubic meters of wood per ha per year, describes the potentially available growing stock separately for logs and other wood (industrial wood).

d Deadwood stock: given as cubic meters per ha, differentiated by the type of wood (coniferous, oak, other broadleaf).

e Greenhouse gas removals/emissions: $\mathrm{CO}_{2}$ removed from the atmosphere through biomass growths and emissions resulting from harvest and biomass decay expressed in tons of $\mathrm{CO}_{2}$ per ha and year, derived from modelled growing stock and biomass functions for other compartments (roots, branches, leaves).

$\mathrm{f}$ Soil carbon changes: expressed in tons $\mathrm{C}$ per ha and year, calculated using a soil carbon model driven by climate parameters and litter composition.

$\mathrm{g}$ Share of old trees: represented by the volume of trees with a diameter of more than $80 \mathrm{~cm}$.

Biomass production in the agricultural and forestry systems was calculated using the simulation model FABio (Forestry and Agriculture Biomass Model), developed at Oeko-Institut (FABio agricultural model: Böttcher et al. 2020; FABio forestry model: Böttcher et al. 2018).

\section{Scenario development}

Three alternative management scenarios were designed for crop and livestock production that include a 'cash crop' scenario, a 'moderate extensification' scenario and a 'strong extensification' scenario. The gradient of intensity becomes evident, particularly when looking at crop rotation parameters, which in the cash crop scenario refer to rules of conventional cultivation (for highly productive areas). The moderate extensification scenario uses adapted cultivation rules (as recommended for less productive sites), characterised by longer 
crop rotations. In the strong extensification scenario, crop rotation and management rules based on organic farming are applied, including also setaside areas (for more details on scenario specifications, please refer to Böttcher et al. 2020).

The forestry production system describes a case of forest conversion from pure spruce forest stands to mixed stands dominated by broadleaved trees. This example is based on data from the German National Forest Inventory (Bundeswaldinventur, BWI). A selection of inventory plots with similar conditions (region, tree species composition, and ownership) was selected and treated as one management unit. Four scenarios were simulated over a period of 100 years. As a business as usual scenario, we considered a continuation of production patterns (current target diameters, no species change), derived from publicly available parameters describing the WEHAM base scenario (BMEL 2016). Two alternative scenarios assume a reduction in management intensity (increased target diameters) and a forest conversion of tree species change towards broadleaved trees (introduction of beech trees in regeneration). A fourth scenario combines scenarios of reduced intensity and forest conversion.

\section{Results}

The sustainable resource output SRO describes effects of changes in the intensity of management on the individual environmental indicators as the product of relative utilisation I' (of natural resources measured by environmental indicators) and relative utility $\mathrm{U}^{\prime}$ (margin). Figure 19.2 shows the results of relative utilisation $\mathrm{I}^{\prime}$, and utility $\mathrm{U}^{\prime}$ (Figure 19.2a and 19.2c) compared to SRO (Figure 19.2b and 19.2d) applied to examples in the agriculture and forestry case studies. High values of SRO indicate a high performance, i.e. low impacts on natural resources paired with high output in terms of revenue. Low values show that the management option either impacts environmental indicators negatively and/or leads to a reduced revenue compared to the other options.

In the agriculture case study, the highest margin is achieved when cash crops are produced (see Figure 19.2a). With moderate and strong extensification, the margin is reduced by $50 \%$. However, cash crop production scores low regarding environmental performance. Regarding the carbon balance of soils, the threshold of $-300 \mathrm{H}$-eq/ha is reached, causing the indicator to be set to zero. Also, in terms of all other indicators, the cash crop option results in lower indicator values with largest differences for the biodiversity indicator. Due to the high relative margin that can be achieved with cash crops, the option performs better when looking at SRO, the product of relative margin and relative utilisation (see Figure 19.2b). On indicators that are relatively close for the alternative options on the common scale, such as GHG emissions and Nitrogen balance in the example, large differences in the utility have a larger impact on relative performance.

In the forestry case study, the highest margin can be achieved with a continuation of business as usual management as it achieves the highest harvestable volume. 

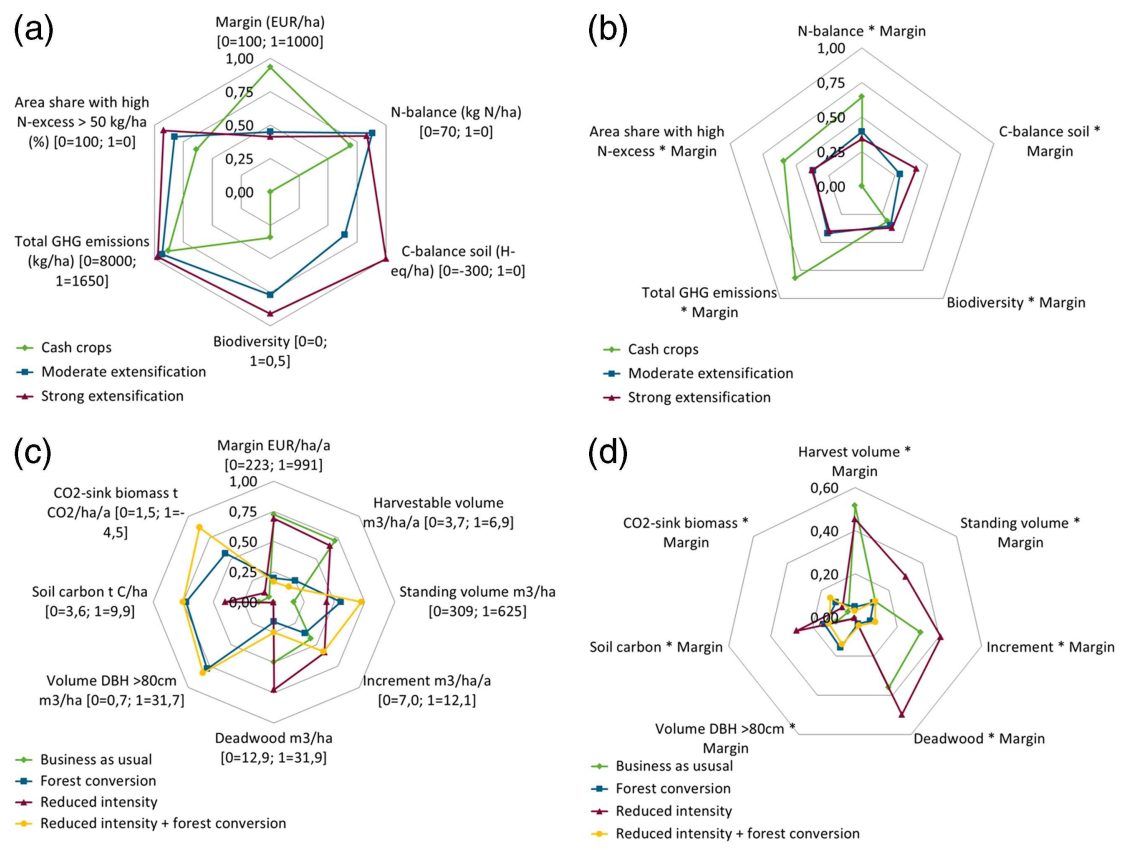

Figure 19.2 Examples for performance of relative utilisation I' (environmental indicators) and utility $\mathrm{U}^{\prime}$ (margin) for case studies on (a) agriculture and (c) forestry, and the resulting sustainable resource output SRO for (b) agriculture and (d) forestry, which allows to assess alternative management options in such biomass production systems (with $\mathrm{SRO}=\mathrm{I}^{\prime} \times \mathrm{U}^{\prime}$ ).

Forest conversion to broadleaved trees reduces the margin considerably, whereas for the reduced intensity only a small reduction can be observed. Figure 19.2c) shows that the options perform very differently regarding the different indicators. While reduced intensity seems to be best for the generation of additional deadwood, reduced intensity combined with forest conversion results in the highest $\mathrm{CO}_{2}$ sink over the simulation period and yields the highest standing volume. Assessing the performance of options using SRO changes the order for a number of indicators, e.g. soil carbon where options including forest conversion result in low values due to relatively low margins that can be achieved (Figure 19.2d). In the case of deadwood, SRO confirms the observation made when ignoring economic performance.

\section{Interpretation and discussion}

The SRO concept expands the concept of resource efficiency and allows a consideration of the multi-dimensional use of natural resources by bringing the dimensions to a common scale of values. Compared to resource efficiency, SRO has the advantage that critical boundaries and thresholds are 
considered, such that increases in efficiency that exceed environmental limits are reflected in the metric. The presented case studies deliver reasonable results and demonstrate the application of the concept. There are, however, a number of challenges that are associated with the approach requiring further assessment and testing.

The selection of indicators should be guided by the purpose of the assessment, directly linking to the environmental concerns to be studied but also needs to reflect system boundaries and data availability. The indicators should be able to adequately reflect the conditions in the production system and its boundaries. Using simulation models, as in this study, allows for a consistent consideration of indicators in one framework but also limits the choice of indicators to model capabilities. A large number of indicators exist, as documented by the SEBI process (EEA 2012) or the MAES initiative (EC 2018). However, particularly with regard to the effects on biodiversity, adequate data is often not available, but also scientific evidence regarding the relationship between management intensity and biodiversity is unclear (Nolet et al. 2018; Sabatini et al. 2019). Combining the approach with a geographical information system would allow detailed spatial representation of indicators.

A major challenge is the selection and implementation of appropriate thresholds and limits as maxima and minima for the scaling of indicators into a common frame. Identifying these values is required to make indicators comparable - similarly to the resource efficiency approach - but also as an input for the calculation of SRO. The choice of maximum and minimum values determines the relative utilisation of natural resources and has therefore strong influence on the value of sustainable resource output in the end. Thresholds might not be easily derived for all indicators, i.e. indicator selection should therefore also consider the availability of such information. We used existing literature values, legal boundary values and also modelled values from sensitivity analyses. We recommend preferably using published literature values for the application of the SRO approach, if that is not possible and values are estimated or generated by models, then a good documentation is crucial.

For plausibility and consistency checks of the values, the following questions should be answered:

i Do the thresholds and limits reflect tolerable magnitudes or loads regarding policy targets or existing legislation?

ii Are thresholds or limits universally valid for the alternative systems analysed?

iii Are the values sufficiently differentiated to make differences in the production systems visible?

Also, for the scaling of utility $U$ (margin), maximum and minimum values need to be defined. The result of SRO is also very sensitive to the choice of these parameters. They should reflect a realistic range of possible values across alternative management options. As in the definition of resource efficiency, SRO 
remains with the monetary value of biomass production. Our case studies took into account only revenues from biomass production and costs of biomass extraction. The concept, however, can be extended to include monetised impacts on ecosystem services to fully include external costs (TEEB 2010, 2018). This could be done by including costs for administrative fines or reduced premiums, payments for ecosystem services, $\mathrm{CO}_{2}$ prices etc. It has to be considered, though, that an inclusion of more aspects into the utility term also requires more efforts to establish adequate and transparent scaling values.

\section{Conclusions}

The concept of SRO extends the concept of resource efficiency in a meaningful way and can be used for the multi-dimensional evaluation of the sustainability of biomass production systems. The advantage against the classical concept of resource efficiency is the inclusion of thresholds to reflect the transgression of sustainability limits of production systems. As the major challenge, we identified the selection of threshold values that need to be carefully chosen and well documented. Future work should seek to refine the SRO concept by exploring different indicators and scaling approaches and to test its integration into existing assessment tools.

\section{List of abbreviations}

$\begin{array}{ll}\text { BWI } & \text { German National Forest Inventory (Bundeswaldinventur) } \\ \text { FABio } & \text { Forestry and Agriculture Biomass Model } \\ \text { GHG } & \text { greenhouse gas } \\ \text { HANPP } & \text { human appropriation of net primary production } \\ \text { I } & \text { utilisation of natural resources } \\ \text { MIPS } & \text { material input per service unit } \\ \text { ProgRess } & \text { German Resource Efficiency Programme } \\ \text { SRO } & \text { sustainable resource output } \\ \text { U } & \text { utility of natural resources }\end{array}$

\section{References}

Albert, C., Bonn, A., Burkhard, B., Daube, S., Dietrich, K., Engels, B., Frommer, J., Götzl, M., Grêt-Regamey, A., Job-Hoben, B., Koellner, T., Marzelli, S., Moning, C. et al. (2016). Towards a national set of ecosystem service indicators: insights from Germany. In: Ecological Indicators 61, pp. 38-48. DOI: 10.1016/j.ecolind.2015.08.050.

BMEL (2016). Wald und Rohholzpotenzial der nächsten 40 Jahre, Ausgewählte Ergebnisse der Waldentwicklungs- und Holzaufkommensmodellierung 2013 bis 2052. Bundesministerium für Ernährung und Landwirtschaft. Berlin, last accessed on 16 Jan 2017.

Böttcher, H., Hennenberg, K. J., and Winger, C. (2018). FABio-Waldmodell Modellbeschreibung Version 0.54. Oeko-Institut e.V. Berlin. Online available at www. oeko.de/fileadmin/oekodoc/FABio-Wald-Modellbeschreibung.pdf. 
Böttcher, H., Hennenberg, K., Wiegmann, K., Scheffler, M., Wolff, F., Hansen, A., MeyerAurich, A., Grundmann, P., and Vedel, D. (2020). Nexus Ressourceneffizienz und Landnutzung - An-sätze zur mehrdimensionalen umweltpolitischen Bewertung der Ressourceneffizienz bei der Bio-massebereitstellung, FKZ 371531103 0. Umweltbundesamt,. Retrieved from www.umweltbundesamt.de/sites/default/files/medien/1410/publikationen/ 2020-03-04_texte_45-2020_nexus-ressourceneffizienz-landnutzung.pdf.

EC (2018). Mapping and assessment of ecosystems and their services: an analytical framework for mapping and assessment of ecosystem condition in EU, 5th MAES Report. European Commission, 2018. Online available at http://catalogue.biodiversity.europa. eu/uploads/document/file/1673/5th_MAES_report.pdf.

EEA (2012). Streamlining European biodiversity indicators 2020: building a future on lessons learnt from the SEBI 2010 process. European Environmental Agency, 2012.

Erb, K.-H. (2015). Land-use indicators. In: International Encyclopedia of the Social \& Behavioral Sciences: Elsevier, pp. 238-244.

Galaz, V., Biermann, F., Crona, B., Loorbach, D., Folke, C., Olsson, P., Nilsson, M., Allouche, J., Persson, Å., and Reischl, G. (2012). 'Planetary boundaries' - exploring the challenges for global environmental governance. In: Current Opinion in Environmental Sustainability 4(1), pp. 80-87. DOI: 10.1016/j.cosust.2012.01.006.

Haberl, H., Erb, K. H., Krausmann, F., Gaube, V., Bondeau, A., Plutzar, C., Gingrich, S., Lucht, W., and Fischer-Kowalski, M. (2007). Quantifying and mapping the human appropriation of net primary production in earth's terrestrial ecosystems. In: Proceedings of the National Academy of Sciences of the United States of America 104(31), pp. 12942-12947. DOI: $10.1073 /$ pnas.0704243104.

Huysman, S., Sala, S., Mancini, L., Ardente, F., Alvarenga, Rodrigo A. F., Meester, S., Mathieux, F., and Dewulf, J. (2015). Toward a systematized framework for resource efficiency indicators. In: Resources, Conservation and Recycling 95, pp. 68-76. DOI: 10. 1016/j.resconrec.2014.10.014.

Klöpffer, W. and Grahl, B. (2012). Ökobilanz (LCA), Ein Leitfaden für Ausbildung und Beruf 2. Nachdruck. Weinheim: Wiley-VCH.

Koponen, K., Soimakallio, S., Kline, K. L., Cowie, A., and Brandão, M. (2018). Quantifying the climate effects of bioenergy - choice of reference system. In: Renewable and Sustainable Energy Reviews 81, pp. 2271-2280. DOI: 10.1016/j.rser.2017.05.292.

Mancini, L., Lettenmeier, M., Rohn, H., and Liedtke, C. (2012). Application of the MIPS method for assessing the sustainability of production-consumption systems of food. In: Journal of Economic Behavior \& Organization 81(3), pp. 779-793. DOI: 10.1016/j.jebo. 2010.12.023.

Nolet, P., Kneeshaw, D., Messier, C., and Béland, M. (2018). Comparing the effects of even- and uneven-aged silviculture on ecological diversity and processes: a review. In: Ecology and Evolution 8(2), pp. 1217-1226. DOI: 10.1002/ece3.3737.

O'Brien, M., Wechsler, D., Bringezu, S., and Arnold, K. (2015). Sachstandsbericht über vorhandene Grundlagen und Beiträge für ein Monitoring der Bioökonomie: Systemische Betrachtung und Modellierung der Bioökonomie. Wuppertal Institut. Wuppertal.

Pavlovskaia, E. (2014). Sustainability criteria: their indicators, control, and monitoring (with examples from the biofuel sector). In: Environmental Sciences Europe 26(1), p. 17. DOI: 10.1186/s12302-014-0017-2.

Rockström, J., Steffen, W., Noone, K., Persson, Ã. ..., Chapin, F. S., Lambin, E. F., Lenton, T. M., Scheffer, M., Folke, C., Schellnhuber, H. J., Nykvist, B., De Wit, C A, Hughes, T. et al. (2009). A safe operating space for humanity. In: Nature 461(7263), pp. 472-475. 
Online available at www.scopus.com/inward/record.url?eid=2-s2.0-70349451894\& partnerID $=40 \& \mathrm{md} 5=5 \mathrm{db} 9 \mathrm{dbf} 18 \mathrm{fe} 00 \mathrm{~b} 3899 \mathrm{ae} 7 \mathrm{~b} 60 \mathrm{c} 2 \mathrm{f} 60 \mathrm{f} 82$.

Sabatini, F. M., Andrade, R. B. de, Paillet, Y., Ódor, P., Bouget, C., Campagnaro, T., Gosselin, F., Janssen, P., Mattioli, W., Nascimbene, J., Sitzia, T., Kuemmerle, T., and Burrascano, S. (2019). Trade-offs between carbon stocks and biodiversity in European temperate forests. In: Global Change Biology 25(2), pp. 536-548. DOI: 10.1111/gcb.14503.

Schmidt-Bleek, F. (1998). Das MIPS-Konzept, Weniger Naturverbrauch - mehr Lebensqualität durch Faktor 10. München: Droemer.

Steffen, W., Richardson, K., Rockström, J., Cornell, S. E., Fetzer, I., Bennett, E. M., Biggs, R., Carpenter, S. R., Vries, W. de, Wit, C. A. de, Folke, C., Gerten, D., Heinke, J. et al. (2015). Sustainability. planetary boundaries, guiding human development on a changing planet. In: Science (New York, N.Y.) 347(6223), p. 1259855. DOI: 10.1126/ science. 1259855 .

TEEB (2010). The Economics of Ecosystems and Biodiversity: Mainstreaming the Economics of Nature: A Synthesis of the Approach, Conclusions and Recommendations of TEEB. The Economics of Ecosystems and Biodiversity. Online available at www.teebweb.org/ourpublications/teeb-study-reports/synthesis-report.

TEEB (2018). TEEB for Agriculture \& Food: Scientific and Economic Foundations. United Nations Environment Programme. Geneva.

United Nations (2015). Transforming our World: The 2030 Agenda for Sustainable Development. Resolution adopted by the General Assembly on 25 September 2015 (A/RES/70/1). United Nations. Online available at https://sustainabledevelopment.un.org/post2015/ transformingourworld.

WBCSD (2006). Eco-efficiency learning module. World Business Council for Sustainable Development. Geneva. Online available at www.wbcsd.org/Projects/Education/ Resources/Eco-efficiency-Learning-Module. 